\title{
SOLVING EXCESS WATER PRODUCTION PROBLEMS IN PRODUCTIVE FORMATION
}

\author{
Ilya Kozyrev ${ }^{1}$, Pavel Zyatikov ${ }^{1}$, and Vera Deeva ${ }^{1, *}$ \\ ${ }^{1}$ National Research Tomsk Polytechnic University, 634050 Tomsk, Russia
}

\begin{abstract}
One of the important developments of the Russian Federation national economy is a petroleum resource. Water shut off techniques are used in the oilfields to avoid the massive water production. We describe a technology for solving excess water production problems focusing on the new gel-based fluid which can be effectively applied for water shutoff. We study the effect of the gel-based fluid solution experimentally to show the feasibility of its treatment the in the near wellbore region to solve the excess water production problem.
\end{abstract}

\section{Introduction}

Petroleum resources are one of the important developments of the Russian national economy. However, the oil production in Russia fell down caused by the deterioration in reserve structure and quality, the high watercut of the oil production, the low productivity of the mature oil fields, and the final stage of the development of the basic production zone. The deterioration of oil reserves connects with water flooding of the productive oilfields. A greater understanding of water formation leads to an improved perception of the scientific progress and the technological development of the oil and gas industry. Excess water production is a very serious problem during waterflooding of reservoir formations. To solve the problem, many kinds of technologies have been developed. The main advanced approaches include squeezing shutoff fluids, which may be either resin-based fluids, or gelbased fluids [1].

The purpose of this paper is first to analyze the behavior of horizontal well of the oilfields then to present a new gel-based fluid which can be effectively applied for water shutoff in the near wellbore region. The results of the experimental study highlight the feasibility of the gel treatment to solve the excess water production problem.

\section{Control of excessive water production}

The analysis of the structure of oil reserves shows that importance of using a new technique and approach to improve the production efficiency and reduce costs of the mature fields. Thus, the important way to stimulate oil production and to increase conformance is to bring into production certain of the horizontal well. At the same time, the water problem occurs in horizontal well which could be solved by applying water-shutoff technologies such as

*Corresponding author: veradee@mail.ru 
gel-based fluids. The injection of water-shutoff gels reduces water production and help address the problem when a high-permeability zone with a flow barrier in horizontal well. Figure 1 demonstrates the fractures and faults intersecting an aquifer in horizontal well [2].

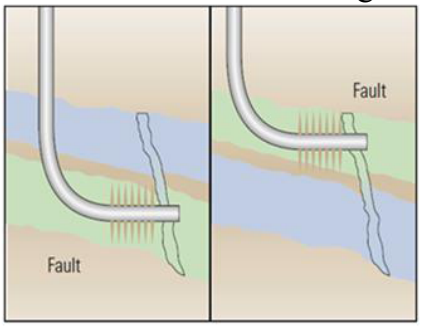

Fig. 1. Fractures or faults from a water layer (horizontal well).

Figure 2 shows the fluid distribution in reservoir containing water, oil and gas before production or injection begins [2].

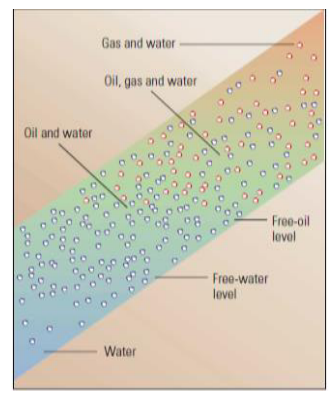

Fig. 2. Typical fluid distribution before production or injection begins.

Furthermore, major drawbacks of the most gel-based fluids are the limited penetration in the matrix and so selectively flow in the fractures, the heat sensibility, toxic property and high cost. Thus, there is a need to investigate effective and reliable gel-based fluids to become an impermeable barrier with a high penetration.

A laboratory study was conducted to characterize watershutoff gels that are injected in the horizontal well into fractures (or other high permeability anomalies) that are in direct contact with production wells. Laboratory experiments estimate the gelling kinetics and the dicalcium silicate $\left(\mathrm{CaCl}_{2}\right)$ rheological properties offering attractive possibilities of obtaining the physical-chemical properties and the gel waterproofing capacity.

Experiments are conducted in strong accordance with standard technique of the surface chemistry and physics of oil formation [3]. Recently, methods of mathematical statistics [4] have been used as supporting materials for calculation and report. We determine the dependence of the gel time on initial reagent concentration and the temperature being nonlinear. The results are confirmed by the law of mass action, so called Guldberg and Waage expression, and Arrhenius equation:

$$
\frac{\partial C}{\partial t}=z_{0} \exp \left(\frac{-E_{a}}{R T}\right) C_{1}^{n} C_{2}^{l}
$$

where $W_{\varphi}-C$ is the gel concentration from a stock solution; $\% ; z_{0}$ is the pre-exponential factor (or simply the prefactor), $\mathrm{s}^{-1} ; \mathrm{R}$ is the universal gas constant; $E_{a}$ is the activation energy, $\mathrm{j} / \mathrm{k} / \mathrm{mol} ; T$ is the temperature, in kelvin; $C_{l}$ is the hydrochloric acid concentration $(\mathrm{HCl})$, unit fraction, $\mathrm{C}_{2}$ is the concentration of the dicalcium silicate $\left(\mathrm{CaCl}_{2}\right)$, unit fraction, $t$ is the gel time, sec. 
The most important of the thermodynamic characteristics during the gel formation is the activation energy $\left(E_{a}\right)$. Overall from this series of experiments (table 1) we find the value of the energy $40 \mathrm{j} / \mathrm{k} / \mathrm{mol}$ using the least square method for data interpretation.

Under initial condition the equation (1) gives us the follow solution: of $n=1.15$, $l=0.51, z_{0}=805235.8 \mathrm{~s}^{-1}$. It could therefore seem that the influence of the salinity of water in the concentration range of 1 to $1.20 \mathrm{~g} / \mathrm{sm}^{3}$ on the gel time is linear (figure 3 ). In this paper we control the salinity of water through the control of the concentration of the solution of $\mathrm{CaCl}_{2}$ and $\mathrm{NaCl}$.

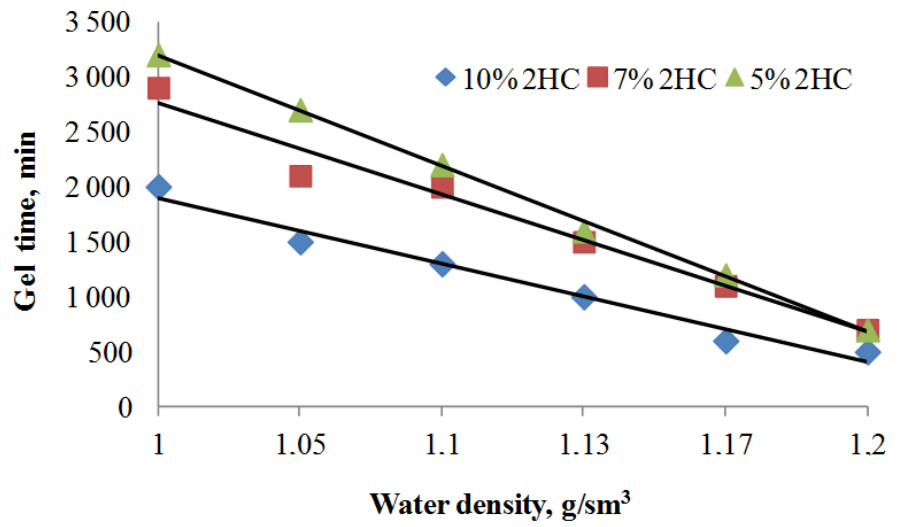

Fig. 3. The dependence of the gel time on the water density (in the temperature $22^{\circ} \mathrm{C}$ and in the concentration of $\mathrm{HCl} 8 \%$ ).

During this laboratory study, we determine the selectivity of the water-shutoff gels which make evidence of the fact that the competent gel is formed in the water-wet core, by comparison the weak gel is formed in the oil-saturated core. We assume that it is connected with the limited adhesive properties of the gels in particular oil-saturated core. Table 1 summarizes the results of experiments and highlights a good gel waterproofing capacity.

Table 1. The characteristic of the near wellbore region.

\begin{tabular}{|l|l|}
\hline \multicolumn{1}{|c|}{ Properties } & \multicolumn{1}{c|}{ Variables } \\
\hline Reservoir types & $\begin{array}{l}\text { Fractured and faulted } \\
\text { formation }\end{array}$ \\
\hline Reservoir temperature, ${ }^{0} \mathrm{C}$ & 32 \\
\hline Formation pressure, $\mathrm{MPa}$ & 7.8 \\
\hline Length of core, $\mathrm{m}$ & $3.510^{-2}$ \\
\hline Diameter, $\mathrm{m}$ & $2.8-10^{-2}$ \\
\hline Porosity, $\%$ & 18 \\
\hline Absolute permeability (under overburden stress 3.4 MPa), $\mu \mathrm{m}$ & 0.08 \\
\hline Flow rate, $\mathrm{m}^{3} / \mathrm{min}^{-6}$ & $5-10^{-6}$ \\
\hline $\begin{array}{l}\text { Water relative permeability under P-T conditions (before water shutoff } \\
\text { treatment), } k_{\text {before }}, \mu \mathrm{m}^{2}\end{array}$ & 0.025 \\
\hline Pressure differential of core (after water shutoff treatment), $\mathrm{MPa} / \mathrm{m}^{2}$ & 12.45 \\
\hline Water relative permeability (after water shutoff treatment), $k_{\text {after }}, \mu \mathrm{m}^{2}$ & 0.007 \\
\hline
\end{tabular}




\section{Discussion of Results}

Thuswise most promising for the application of this gel-based fluid is to minimize the excess water in the near wellbore region. The injection of a water-shutoff gel could reduce water production without affecting oil production from the formation.

It should be mentioned that LLC "Burneftegas" effectively applies this gel for water shutoff hydraulical fracturing in an injector well.

Moreover, in one producing well of Sorovskoe field the water-handling capacity to cope with up to $90 \%$ during choke-back. After squeezing shutoff fluid based on silicon coating backfill materials AKOR-BN 102, the ratio of the produced fluid is reduce more than $40 \%$, at the same level of the production rate (around $10 \mathrm{~m}^{3} /$ per day) [5].

Similar results were obtained by JSCo "Tatneftprom". After squeezing shutoff fluid based on polymeric composition "MPS REIS-H" in the Ivninskoe field the production rate is increased 8 -fold while the average water cut is reduced by $20-28 \%$ [6].

\section{Conclusion}

What is clear about petroleum is that it will continue to play a large role in our lives. For mature fields, as a complex subject in the oil and gas industries, several types of oil production and distribution problems are posed: selection of crude oil, water flooding, particle coarsening [7] and others. Excessive water production and has a serious economic and environmental impact thus How to control water-cut of mature oilfields is always a challenging task for field operators. This paper considered new gel that can impart large permeability reduction factors for water flow in productive formation. Our results imply that ineffective gel treatment is responsible for attaining smaller water-shutoff values in the field than in the laboratory.

\section{References}

1. J. Elphick and R. Seright, Petroleum Network Education Conference's 3rd Annual International Conference on Reservoir Conformance Profile Modification, Water and Gas Shutoff, Houston, Texas, USA, August (1997)

2. B. Bailey, J. Tyrie, J. Elphick, et al., Oilfield Rev. 12, 1 (2000)

3. B.M. Kurochkin, Instructions to proceed insulation works with the application of water-swellable polymer (SPA “Drilling equipment", USSRVT, Moscow, 2002)

4. S.M. Slobodyan, Meas. Tech. 49, 1 (2006)

5. V.M. Stroganov, Project development and application of the silicon coating backfill materials (LLC SPF "Nitpo", Krasnodar, 2009)

6. I.P. Novikov, A.S. Primachenko, V.M. Lapshina, Oil-gas exposition 2, 41 (2015)

7. M.V. Vasilevsky, P.N. Zyatikov, A.Y. Burykin, V.S. Deeva, IOP Conf. Ser.: Earth Environ. Sci. 27, 012020 (2015) 